\title{
The association between antibiotics in the first year of life and child growth trajectory

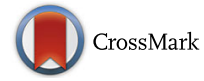

Elizabeth E. Dawson-Hahn ${ }^{1,2}$ (D) and Kyung E. Rhee ${ }^{3^{*}}$

\begin{abstract}
Background: Antibiotics are frequently prescribed to children, and may be an environmental influence that contributes to the increasing prevalence of childhood obesity. The aim of this study was to examine the effect of antibiotic use in the first year of life on child growth trajectories from birth to age 6 years including significant covariates.

Methods: Data from 586 children in the Infant Feeding Practices II (IFPS II) and 6 year follow-up study (6YFU) were included. Antibiotic exposures, weight and height measurements were collected from birth through the first 12 months, and then again at 6 years. Linear mixed effects growth modeling, controlling for exclusive breastfeeding, socio-demographic factors, smoking during pregnancy, gestational diabetes, and maternal pre-pregnancy weight status, was used to examine the association between antibiotic exposure and child growth trajectories through age 6 years.

Results: The majority of infants (60.58\%) did not receive any antibiotics; $33.79 \%$ received $1-2$ courses and $5.63 \%$ received 3 or more antibiotic courses during the first year. In the unadjusted model, children with 1-2 antibiotic exposures had a 0.17 (SE 0.08) higher rate of change in BMI z-score (BMIz) than children without any antibiotics, and children with $\geq 3$ exposures had a 0.42 (SE 0.16) higher rate of change in BMIz $(p=0.009$ ). Growth trajectory over time for those who had $\geq 3$ antibiotics was greater than those without any antibiotics $(p=0.002)$.
\end{abstract}

Conclusions: Efforts to guide the judicious use of antibiotics should continue, particularly in the first year of life.

Keywords: Antibiotics, Pediatrics, Growth, Weight status, Breastfeeding

\section{Background}

Children receive antibiotics in over $20 \%$ of ambulatory visits in the United States. [1] Despite the clear benefits of antibiotics for specific illnesses, they can also have unintended consequences including antimicrobial resistance [2] and the development of atopy and inflammatory bowel disease (IBD). [3, 4] Recently, there has been growing interest in the association between antibiotics and increased weight status. [5-13] The association between antibiotic exposure and the development of these chronic diseases is postulated to be through alterations to the gut microbiota. At this time, studies have shown that the make-up of the gut microbiota varies between overweight and normal weight

\footnotetext{
* Correspondence: k1rhee@ucsd.edu

${ }^{3}$ Department of Pediatrics, UCSD School of Medicine, University of California San Diego, 9500 Gilman Drive, MC 0874, La Jolla, CA, San Diego, CA 92093, USA

Full list of author information is available at the end of the article
}

individuals, [14] and that changes in weight are associated with changes in the gut microbiota. [15] Often, a higher proportion of microbiota from the Bacteroidetes phylum are present in lean individuals and a higher proportion of Firmicutes in obese individuals. [16-18] Administration of antibiotics can acutely alter the composition of the gut microbiota, leading to decreased microbial load and phylogenetic diversity, and ultimately the overgrowth of bacteria that have increased capacity to harvest energy from one's dietary intake and promote excess weight gain. [19-21] In animal studies repeated early antibiotic exposures lead to perturbations in the gut microbiota and sustained changes in the metabolic profiles of mice. [22] These changes can remain for several years and long-term use of antibiotics may lead to permanent changes in the gut microbiota. [23]

Several human studies have suggested an association between childhood antibiotic exposure and weight

(c) The Author(s). 2019 Open Access This article is distributed under the terms of the Creative Commons Attribution 4.0 International License (http://creativecommons.org/licenses/by/4.0/), which permits unrestricted use, distribution, and 
status. [5-10, 13, 24-26] These studies have occurred in the UK, Finland, Denmark, the Netherlands, Canada, and the US, and have primarily focused on oral antibiotic exposure at $<2$ years old and risk of obesity between 2 and 12 years old. While these cohorts have enhanced our understanding of the relationship between antibiotics and child weight status, several of them did not control for key factors known to affect child weight status and growth, $[5,6,10,12,13]$ such as maternal BMI, gestational diabetes, and breastfeeding status. [27-31] Breastfeeding is associated with the development of a gut microbial pattern that may influence weight gain trajectories and metabolic profiles. Infants who are breastfed have a lower risk of being overweight. Additionally, breastfeeding is associated with both weight status and antibiotic receipt. [32-34] Higher maternal weight status and gestational diabetes are also associated with increased weight status [29-31] and has not been included in many of the previously mentioned studies. [5-7, 10, 12, 13] As such, it is important to control for these variables as we examine the relationship between antibiotic use and early weight gain.

Our goal was to further examine the relationship between antibiotic use in the first 12 months and its effect on growth trajectories during the first 6 years. Using the Infant Feeding Practices II (IFPSII) survey and 6-Year Follow-Up study (6YFU), we aimed to examine growth trajectories using mixed effects linear regression models controlling for many of the covariates associated with childhood obesity and antibiotic use, including breastfeeding and maternal BMI that have not consistently been included in previous analyses.

\section{Methods}

\section{Study sample}

Data from the Infant Feeding Practices Study II (IFPS) [35], which followed mother-infant pairs from late pregnancy through the infants' first year of life, and the 6 year follow-up study (Y6FU) [36] were included. The study was conducted by the US Food and Drug Administration in collaboration with the Centers for Disease Control and Prevention (CDC) drawing from a nationally distributed consumer opinion panel from May 2005 to June 2007. The study was designed to better understand infant feeding practices and factors that influence infant feeding, infant health, and maternal health and diet. Details regarding the IFPS II have been previously published. [35] Mothers were eligible to participate in the study if they were $\geq 18$ years old at the prenatal questionnaire, were having a singleton infant born at $\geq 35$ weeks gestation and if the infant weighed $\geq 5$ pounds at birth. Neither the mothers nor the infants were eligible if they had a medical condition that could impact feeding. Mothers received questionnaires by mail at 7 months gestation, birth, the neonatal time point ( 3 weeks old), and post-natal months $2,3,4,5,6,7,9,10$, and 12 . Initially 1807 women completed questionnaires through the first 12 months of life. In 2012, the 6YFU questionnaire was sent to infant-mother pairs who participated in the IFPS II study, and a total of 1542 questionnaires were completed (Fig. 1). [36]

Of the 1542 mothers who completed the 6YFU questionnaire, only 985 provided the weight, height, and date of their child's primary care visit in order for 72 month BMI z-score to be calculated. Additional subjects were excluded if infants were less than 37 weeks gestation ( $n$ $=65)$ or mothers were underweight $(\mathrm{BMI}<18.5)$ at the pre-pregnancy time point $(n=84)$. Infants who did not have anthropometric data (weight and/or length/height) or the date of the primary care physician visit at $0,2,4$, 6,12 , and 72 months) were dropped from the analysis. Children with a weight-for-length (WLz) z-score or BMI $\mathrm{z}$-score less than -5.0 or greater than 5.0 were considered outliers and also dropped from the analysis. As a result, 586 infants were included in the final analysis (Fig. 1). This study was deemed exempt by the Institutional Review Board of the University of California, San Diego.

\section{Measures \\ Exposure}

The use of antibiotics during the first year of life was asked on all questionnaires between 2 months and 12 months of age. Mothers were asked a yes/no question: "Did your baby receive any of the following medicines in the past 2 weeks?" with "antibiotics" being one of the options. [37] Infants had anywhere from 0 to 8 courses of antibiotics in the first year of life. Antibiotic use was then categorized as none, 1-2 courses, and 3 or more courses for the analysis.

\section{Outcome}

The primary outcome variables were infant WLz at 2, 4, 6 and 12 months and BMI z-score (BMIz) at 72 months. Mothers reported the child's weight in pounds and length in inches from the child's 2, 4, 6, 12 and 72 well-child visit to the primary care provider. Overweight/Obese status in children at age 6 years was defined by having a BMI $\mathrm{z}$-score $\geq 1.64$ (BMI $\geq 95$ th percentile per CDC guidelines). [38] The date of each measurement was reported and the child's age was determined by calculating the difference between the infant's birth date and the reported date of the primary care visit. Average age at these visits were: 2 months, $68.32 \pm 13.85$ days; 4 months, $126.10 \pm 15.47$ days; 6 months, $191.82 \pm 19.07$ days; 12 months, $362.38 \pm 24.28$ days; 72 months, 336.14 weeks 


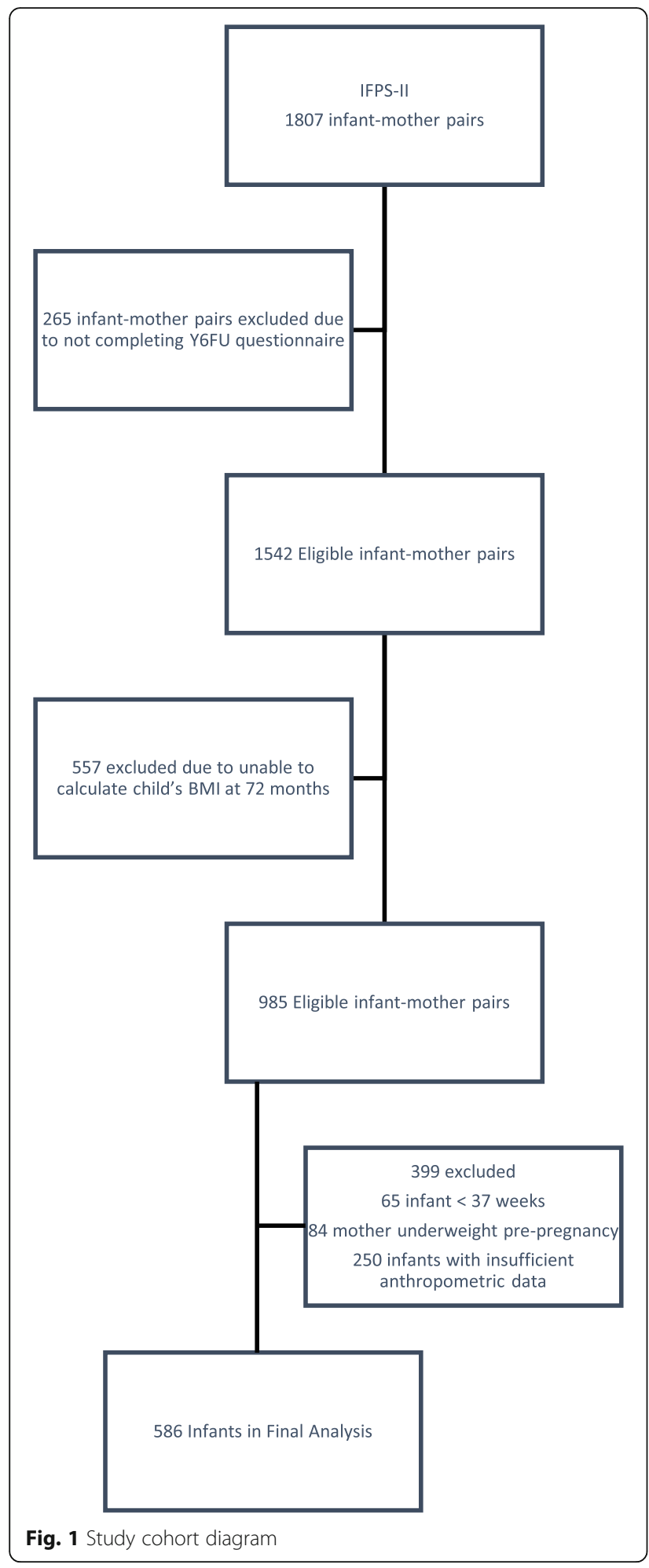

\pm 10.14 weeks. Infant $\mathrm{WLz}$ from 0 to 12 months and BMIz at 72 months were calculated based on the 2000 Centers for Disease Control and Prevention (CDC) infant and child growth charts [39].

\section{Covariates}

We included several covariates in our model. Maternal socio-demographic characteristics included maternal age, race, marital status, annual household income, and education. Maternal self-reported race was categorized as white vs. non-white. Marital status was dichotomized as married vs. single (which included never married, divorced, separated or widowed). Since the median household income of our sample was $\$ 40,000$, this variable was dichotomized into $\geq \$ 40,000$ vs. $<\$ 40,000$. The median number of years mothers spent in school was 16 years, therefore, maternal education was dichotomized into $\geq 16$ years (college graduate) vs. < 16 years (some college or below). Maternal pre-pregnancy weight status is associated with infant weight gain and growth, [40] and maternal BMI was divided into one of three BMI categories: normal weight $=18.50-24.99$, overweight $=25.00-29.99$, and obese $\geq 30$. Gestational diabetes has also been associated with overweight status and was included in the model. [29-31] Mothers were categorized as having diabetes if they reported having gestational diabetes, juvenile onset diabetes, or adult onset diabetes during their pregnancy. Maternal smoking has been associated with infant weight status and overweight risk, [41] and was therefore included in the model. Breastfeeding has been associated with both infant weight status in childhood, [42] as well as risk of infection in children. [43] While the American Academy of Pediatrics (AAP) recommends exclusively breastfeeding for 6 months, most mothers-infant pairs do not exclusively breast feed for that duration. [44, 45] The CDC National Immunization Survey reported that only $18.8 \%$ of infants born in 2011 exclusively breastfed for six months while $32.9 \%$ exclusively breastfed for four months. [46] Therefore, we included exclusive breastfeeding for 4 months as a covariate. Infant sex was also included in the model.

\section{Analysis}

Statistical analysis was conducted using SAS 9.4 software (Cary, NC). Means and frequencies were used to describe the sample. Simple unadjusted bivariate analyses were conducted using generalized linear models (GLM) or chi-square statistics to determine whether WLz/BMIz and covariates differed between the three antibiotic groups. Using PROC MIXED in SAS and tested for fixed and random effects, we conducted linear growth modeling of 0 (birth), 2-, 4-, 6-, 12- and 72-month assessments with final models including planned adjustments for covariates described above. First we estimated the unconditional growth model with no covariates to examine the relative fit of random intercept models with and without allowance of individual random slopes. Tests of nested models suggested that adding a random effect for linear slope improved model fit (-2 log likelihood decreased 
from 10,920 to 10,611$)$. Next, we compared the relative fit of a linear model that also included a term to capture differences in the rate of acceleration in weight changes over time with a quadratic effect $\left(\right.$ time $\left.^{2}\right)$. The model with the quadratic effect improved fit significantly $(-2$ $\log$ likelihood decreased from 10,288 to 10,175) over a model with only a linear effect of time. Therefore, subsequent models included both linear and quadratic effects to describe changes in WLz/BMIz over time. A dummy coded index for antibiotic use group was tested to examine whether there were differences in overall levels of WLz/BMIz across time points (Model 1) and whether interactions between antibiotic group and time suggested that the linear or quadratic rate of change in WLz/BMIz differed across groups (Model 2). The final model (Model 3) included adjustments for covariates known to impact infant/child weight status, including maternal age, maternal BMI, race, marital status, income, education, smoking, diabetes, exclusive breastfeeding for 4 months, and infant sex. Statistical significance was set at $p \leq 0.05$ for all analyses.

\section{Results}

Children had a mean birth weight of $3.50 \mathrm{~kg}$ (S.D. 0.46) (Table 1). By the age of 72 months, $11.09 \%$ were either overweight or obese. Antibiotic use ranged from 0 to 8 courses over the first 12 months. The majority of infants $(60.58 \%)$ did not receive any antibiotics; $33.79 \%$ received 1-2 antibiotic courses and $5.63 \%$ received 3 or more antibiotic courses during the first year. In total, a little over half the mothers were either overweight $(27.82 \%)$ or obese $(23.55 \%)$ at the pre-pregnancy time point. Over half the sample $(55.46 \%)$ had a college degree or higher, and $30.21 \%$ exclusively breast fed for at least 4 months. Demographic characteristics of those who received $0,1-$ 2 , or $3+$ antibiotics courses did not differ significantly from each other except for maternal education. Those who received $3+$ antibiotic courses were more likely to have a college degree or higher (Table 1).

In the mixed effects linear growth model, we assessed the effect of linear time, quadratic time and antibiotic course on child growth (Table 2). In the unconditional model (not shown), the Intra Class Correlation coefficient indicated that $25.7 \%$ of the variance in growth was accounted for by differences between children. In model 1 , we observed significant increases in WLz/BMIz over time (linear time; $p<0.0001$ ) and that rates of change in WLz/BMIz differed across 2-, 4-, 6-, 12- and 72-month assessments (quadratic time; $p<0.0001$ ). Across assessments, infants who had 3+ antibiotics in the first year had a 0.42 (S.E. 0.16) higher WLz/BMI z-score than infants who had no antibiotics $(p=0.009)$. However in Model 2, we observed a significant interaction between antibiotic group and the quadratic effect of time $(p=0.003)$. Infants who had 3+ antibiotic courses had a more rapid increase in their rate of growth over time (i.e. the quadratic effect; $p=0.003)$. This interaction remained statistically significant after adjusting for covariates in Model 3. Figure 2 presents covariate-adjusted changes in WLz/BMIz over 2-, 4-, 6-, 12-, and 72-month assessments for infants in the antibiotic exposure groups.

\section{Discussion}

In this observational cohort study, we found that antibiotic use was independently associated with increased growth during early childhood. The dose-response relationship between antibiotic exposure and child weight status, demonstrated in our study and supported by prior studies $[5,6,13,24,26]$ provides additional support for judicious antibiotic prescribing during early childhood. Finally, evidence of a relationship between antibiotic exposure and growth trajectory in a US cohort with good breastfeeding ascertainment is a key contribution given that breastfeeding has not been included as a covariate in prior US studies. $[5,6,12,24]$

It is important to consider that this association held true while controlling for exclusive breastfeeding status, a factor thought to affect weight gain in infancy, antibiotic prescribing, and gut microbiota composition, and the impact of antibiotics on the gut microbiome. [27, 47] Breastfeeding status can be challenging to determine from health records and therefore, was included in some $[7-9,25]$ but not all prior studies in this area. $[5,6$, 13, 24] Since the postulated mechanism leading to the association between antibiotic exposure and weight status is through the gut microbiota, and breastfeeding is an important early contributor to the gut microbiota, [48] inclusion of breastfeeding is key to understanding this relationship. A study in Finland found that antibiotic exposure while breastfeeding may attenuate the beneficial effects of exclusive breastfeeding, [34] i.e., children who are exposed to antibiotics may not have the lower weight that would be anticipated of breastfed babies.

The dose response effect that we found between antibiotic exposure and weight status supports the findings of the majority of the cohorts that evaluated this relationship previously. A study in Finland examining a population-based cohort of children under 24 months old found that children had a 0.18 higher BMIz when exposed to $\geq 4$ antibiotic courses between 0 and 24 months compared to a 0.10 higher BMIz in those exposed to 2-3 courses. [13] In Central Pennsylvania, there was a similar dose-response effect for antibiotic exposure and child BMI when the child's antibiotic exposure was $\geq 4$ doses for children in the first three years of life. [24] Additionally, a study conducted among older children (3-18 years old) in the same Pennsylvania 
Table 1 Sample Characteristics of children and mothers stratified by antibiotic dose categories $(n=586)$

\begin{tabular}{|c|c|c|c|c|c|}
\hline & Total Sample $n=586$ & No antibiotics $n=355$ & $1-2$ antibiotics $n=198$ & $3+$ antibiotics $n=33$ & $p$-value \\
\hline \multicolumn{6}{|l|}{ Mother: } \\
\hline Age (years; mean $\pm S D$ ) & $30.95( \pm 5.12)$ & $30.95( \pm 5.07)$ & $31.08( \pm 5.22)$ & $30.24( \pm 5.08)$ & 0.69 \\
\hline Gestational weight gain $(\mathrm{kg}$; mean $\pm \mathrm{SD}$ ) & $13.58( \pm 5.96)$ & $13.49( \pm 5.70)$ & $13.81( \pm 6.05)$ & $13.10( \pm 8.02)$ & 0.75 \\
\hline \multicolumn{6}{|l|}{ Pre-pregnancy WeightStatus ${ }^{\mathrm{a}}$ : (\%) } \\
\hline Normal weight & 48.63 & 49.01 & 48.99 & 42.42 & 0.73 \\
\hline Overweight & 27.82 & 27.61 & 28.28 & 27.27 & \\
\hline Obese & 23.55 & 23.38 & 22.73 & 30.30 & \\
\hline White vs. Other (\%) & 91.64 & 90.99 & 91.41 & 100.00 & 0.20 \\
\hline Married vs. Single (\%) & 88.57 & 89.01 & 86.87 & 93.94 & 0.46 \\
\hline Income $(\geq \$ 40,000)(\%)$ & 68.77 & 69.58 & 65.66 & 78.79 & 0.28 \\
\hline Education ( $\geq$ college grad) (\%) & 55.46 & 57.75 & 48.99 & 69.70 & 0.03 \\
\hline Smoked during pregnancy (\%) & 5.12 & 3.94 & 6.57 & 9.09 & 0.23 \\
\hline Gestational Diabetes Mellitus ${ }^{\mathrm{b}}(\%)$ & 9.04 & 9.30 & 9.09 & 6.06 & 0.82 \\
\hline Exclusive Breast Feeding $\times 4$ mos (\%) & 30.21 & 32.85 & 25.51 & 30.30 & 0.20 \\
\hline Vaginal Delivery (\%) & 69.97 & 70.42 & 69.70 & 66.67 & 0.90 \\
\hline \multicolumn{6}{|l|}{ Infant: } \\
\hline Sex: Male (\%) & 48.89 & 49.15 & 50.00 & 39.39 & 0.52 \\
\hline OW/OBC at 72 months (\%) & 11.09 & 8.17 & 14.65 & 21.21 & 0.01 \\
\hline \multicolumn{6}{|l|}{ Antibiotic Course: (\%) } \\
\hline 0 & 60.58 & & & & \\
\hline $1-2$ & 33.79 & & & & \\
\hline $3+$ & 5.63 & & & & \\
\hline Birth weight (kg; mean $\pm \mathrm{SD}$ ) & $3.50( \pm 0.46)$ & $3.49( \pm 0.45)$ & $3.51( \pm 0.48)$ & $3.48( \pm 0.44)$ & 0.78 \\
\hline \multicolumn{6}{|l|}{ WL z-score (mean $\pm S D):$} \\
\hline 0 mos & $-0.46( \pm 1.34)$ & $-0.43( \pm 1.35)$ & $-0.54( \pm 1.32)$ & $-0.27( \pm 1.31)$ & 0.48 \\
\hline 2 mos & $0.02( \pm 1.52)$ & $-0.07( \pm 1.43)$ & $0.15( \pm 1.68)$ & $0.38( \pm 1.37)$ & 0.15 \\
\hline 4 mos & $0.02( \pm 1.50)$ & $-0.08( \pm 1.47)$ & $0.12( \pm 1.54)$ & $0.48( \pm 1.53)$ & 0.10 \\
\hline $6 \mathrm{mos}$ & $0.17( \pm 1.64)$ & $-0.02( \pm 1.59)$ & $0.43( \pm 1.68)$ & $0.79( \pm 1.59)$ & $<0.01$ \\
\hline 12 mos & $0.11( \pm 1.58)$ & $-0.01( \pm 1.57)$ & $0.32( \pm 1.59)$ & $0.27( \pm 1.65)$ & 0.11 \\
\hline BMI z-score (mean \pm SD): 72 mos & $0.31( \pm 1.23)$ & $0.24( \pm 1.15)$ & $0.37( \pm 1.30)$ & $0.67( \pm 1.55)$ & 0.14 \\
\hline
\end{tabular}

${ }^{a}$ Maternal pre-pregnancy weight status was classified by the following definitions: normal weight $=18.5-24.99$, overweight $=25-29.99$, obese $\geq 30$ ( mean $=36.03$, S.D. 5.40)

${ }^{\mathrm{b}}$ Maternal diabetes was defined as self-report of gestational diabetes, juvenile onset diabetes, or adult onset diabetes during or prior to pregnancy

WL z-score $=$ Weight-for-length z-score

BMI z-score $=$ Body Mass Index z-score

${ }^{\mathrm{C}} \mathrm{OW} / \mathrm{OB}=$ Overweight/Obese; Children were identified as being OW/OB if they had a BMI $\mathrm{z}$-score $\geq 1.64$

health system found a dose-response relationship with the BMI trajectory of those who received $>7$ antibiotic courses compared to those who received fewer courses. [6] Another study among children $<5$ years old in urban health centers in Philadelphia found that children also did not exhibit a dose response relationship until they received $\geq 4$ courses of antibiotics in the first 24 months of life. [5] Interestingly, a study in Canada did not find a dose response relationship between antibiotic exposure at $<12$ months and overweight status by the time children were 12 years old. [7] This result may reflect differences in how the exposure was assessed (i.e., medical record data vs. provincial prescription records).

For an average height 72 month old girl in our cohort $(114 \mathrm{~cm})$, a child exposed to $\geq 3$ courses of antibiotics in the first year of life would have a $0.82 \mathrm{~kg}$ higher weight than a child who was not exposed to antibiotics in the first year. This would lead to a 0.4 BMIz score difference between the two children. While this difference may be subtle at 72 months old, childhood overweight at 60 
Table 2 Linear growth model of Weight-for-Length/BMI z-score from birth to 72 months based on antibiotic exposure during the first year of life $(n=586)$

\begin{tabular}{|c|c|c|c|c|c|c|}
\hline & Model 1 & & Model 2 & & Model 3 & \\
\hline & Estimate (S.E) & $P$-value & Estimate (S.E) & P-value & Estimate (S.E) & P-value \\
\hline Initial WL/BMI z-score (intercept) & $-0.21(0.05)$ & $<0.0001$ & $-0.18(0.05)$ & 0.0006 & $-0.10(0.35)$ & 0.77 \\
\hline Linear time (months) & $0.06(0.007)$ & $<0.0001$ & $0.04(0.009)$ & $<0.0001$ & $0.04(0.009)$ & $<0.0001$ \\
\hline Quadratic time (months2) & $-0.0007(0.0001)$ & $<0.0001$ & $-0.0005(0.0001)$ & $<0.0001$ & $-0.0004(0.0001)$ & $<0.0001$ \\
\hline Antibiotic course & & 0.009 & & 0.09 & & 0.10 \\
\hline 0 & 0 & & 0 & & 0 & \\
\hline $1-2$ & $0.17(0.08)$ & & $0.10(0.09)$ & & $0.08(0.09)$ & \\
\hline $3+$ & $0.42(0.16)$ & & $0.37(0.18)$ & & $0.38(0.18)$ & \\
\hline Linear Time $x$ Antibiotic course & & & & 0.003 & & 0.002 \\
\hline 0 & & & 0 & & 0 & \\
\hline $1-2$ & & & $0.05(0.02)$ & & $0.05(0.02)$ & \\
\hline $3+$ & & & $0.04(0.03)$ & & $0.04(0.03)$ & \\
\hline Quadratic Time $\times$ Antibiotic course & & & & 0.003 & & 0.002 \\
\hline 0 & & & 0 & & 0 & \\
\hline $1-2$ & & & $-0.0007(0.0002)$ & & $-0.0008(0.0002)$ & \\
\hline $3+$ & & & $-0.0005(0.0004)$ & & $-0.0005(0.0004)$ & \\
\hline
\end{tabular}

The models presented here included a random statement for the individual allowing variation in intercept, time, time2, and antibiotic course with a variance components (VC) covariance structure between the effects using a Maximum Likelihood Estimation method. Model 1 includes the effect of time, time2, and antibiotic dose on weight-for-length/BMI z-score changes from birth to 72 months. In Model 2, we included the variables for time $x$ antibiotic course and time $2 x$ antibiotic course. Model 3 controlled for known covariates including maternal age, maternal BMI, race, marital status, income, education, smoking, diabetes, exclusive breastfeeding for 4 months, and infant sex. Entries show parameter estimates and standard errors in parentheses.

\section{WL/BMI z-score for children with and without antibiotic exposure}

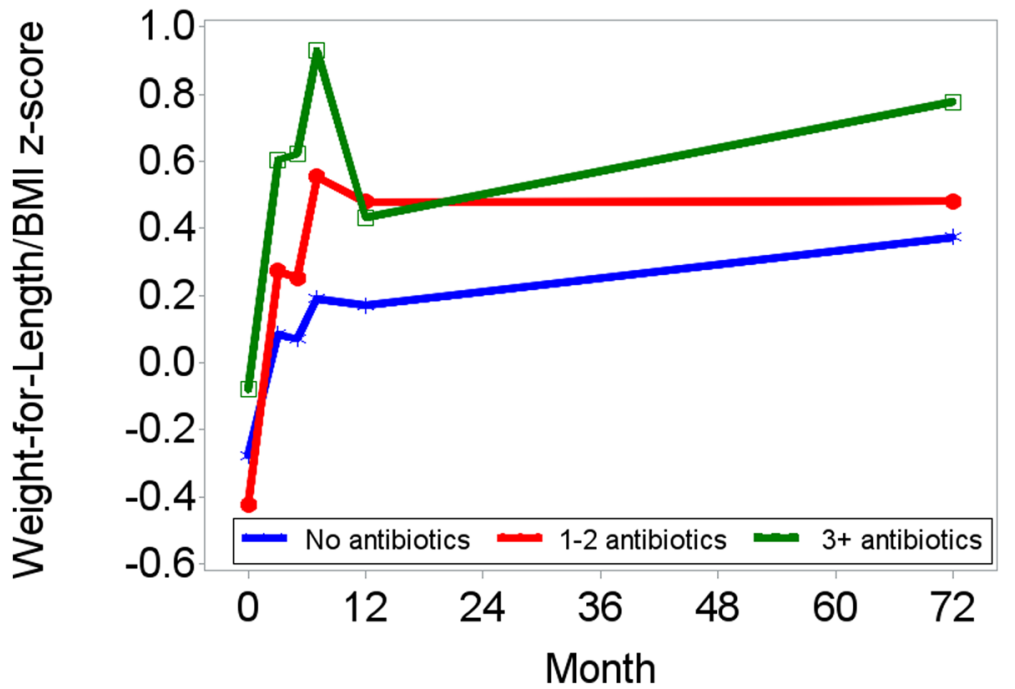

Fig. 2 Growth model examining the effect of antibiotic course on Weight-for-Length/BMl z-score from birth to 6 years. Displays the growth trajectories of children from birth to 6 years based on the number of antibiotic courses the child received from birth to 12 months. The model controlled for known covariates for infant/child weight status, including maternal age, maternal BMI, race, marital status, income, education, smoking, diabetes, exclusive breastfeeding for 4 months, and infant sex 
months old tracks into adolescence [49] and adulthood [50], therefore, a higher BMIz score at 72 months places children at a higher risk of overweight in adulthood. We chose to model growth trajectories over time because it allowed for a more sensitive analysis of the observed differences at 72 months while controlling for the correlation over time between each subject's weight and height data. Further studies are warranted to follow children into adulthood to determine the life course implications of early and continued childhood antibiotic exposure.

While this study adds to the growing literature that antibiotic use in infancy may affect weight status in childhood, there were limitations. The study includes 586 children, and the demographics of the sample are not representative of the broader US population. [35] This study was a retrospective observational study that depended on parental recall of the child's height and weight from the doctor's office, and antibiotic receipt in the last 2 weeks. [35] Recall bias could impact the exposure and outcome in our study. However, the proportion of children with no antibiotic exposure in the first year of life is similar in this cohort as has been reported in other studies, [51, 52] and the proportion of children who were overweight/obese is lower than is reported nationally. Further, each of the scales utilized, and the individuals completing the measurements were at different clinical sites which likely contributed to variability in anthropometric data. This study does include data on the frequency of antibiotic use during the first 12 months, which allowed us to examine the dose-response relationship. However, we may be underestimating the effect of antibiotics because mothers were not asked to record any interceding antibiotic courses the child may have received prior to the past 2 weeks. Furthermore, they were not asked to report on antibiotic use between 12 months and 6 years, limiting our ability to examine the effect of continued antibiotic use on later weight status or weight gain trajectories. Unfortunately, we were also unable to report on the type of antibiotic the child received, or the duration of antibiotic use. This information may have been useful since prior research reports that broad spectrum antibiotics are associated with a higher risk of obesity development. [5] Given these limitations, a prospective study is warranted to more clearly define the relationship between antibiotic use and weight status.

\section{Conclusions}

Children exposed to antibiotics prior to one year of age demonstrated a dose-response effect on growth trajectories while adjusting for key covariates. This finding contributes to the growing body of literature that suggests that antibiotic exposure may be contributing to the prevalence of obesity among children, and demonstrates a key area for physicians to intervene. While we generally think of early childhood as an important time to treat infections due to the vulnerability of children with an underdeveloped immune system, the cost of treatment may incorporate risk for other conditions including obesity and obesity-associated chronic disease. Therefore, judicious use of antibiotics, especially during the first year of life, and acknowledging the risk of obesity with administration is warranted and required conversation between physicians and parents.

\section{Abbreviations \\ (IBD): Inflammatory bowel disease; 6YFU: 6 year follow-up study; AAP: American Academy of Pediatrics; BMIz: BMI z-score; CDC: Centers for Disease Control and Prevention; IFPS II: Infant Feeding Practices II; WLz: Weight/Length z-score}

\section{Acknowledgements}

We would like to thank David Strong, PhD for carefully reviewing the methods and overall manuscript.

\section{Funding}

Dr. Dawson-Hahn's salary was funded by the Ruth L. Kirchstein National Research Service Award (T32HP10002).

Availability of data and materials

The data analyzed in the current study was available from the Infant Feeding Practices Study II (IFPS II), conducted by the Food and Drug Administration (FDA) and the Centers for Disease Control and Prevention (CDC). For access to the files, please send an e-mail request to ifps@cdc.gov.

\section{Authors' contributions}

KR analyzed and interpreted the data, and contributed to the writing of the manuscript. EDH interpreted the data, and drafted the manuscript. All authors have read and approved the manuscript.

\section{Ethics approval}

This study was deemed exempt by the Institutional Review Board of the University of California, San Diego.

Consent for publication

Not applicable.

Competing interests

The authors declare that they have no competing interests.

\section{Publisher's Note}

Springer Nature remains neutral with regard to jurisdictional claims in published maps and institutional affiliations.

\section{Author details}

${ }^{1}$ Department of Pediatrics, University of Washington, Seattle, WA, USA. ${ }^{2}$ Seattle Children's Research Institute, Center for Child Health, Behavior and Development, M/S CW8-6, PO Box 5371, Seattle, WA 98145, USA.

${ }^{3}$ Department of Pediatrics, UCSD School of Medicine, University of California San Diego, 9500 Gilman Drive, MC 0874, La Jolla, CA, San Diego, CA 92093, USA.

Received: 27 April 2018 Accepted: 4 December 2018 Published online: 16 January 2019

\section{References}

1. Hersh AL, Shapiro DJ, Pavia AT, Shah SS. Antibiotic prescribing in ambulatory pediatrics in the United States. Pediatrics. 2011;128(6):1053-61. 
2. World Health Organization: Antimicrobial resistance: global report on surveillance. 2014. http://apps.who.int/iris/bitstream/handle/10665/112642/ ?sequence=1. Last accessed: 13 Dec 2018.

3. Kummeling I, Stelma FF, Dagnelie PC, Snijders BE, Penders J, Huber M, van Ree R, van den Brandt PA, Thijs C. Early life exposure to antibiotics and the subsequent development of eczema, wheeze, and allergic sensitization in the first 2 years of life: the KOALA birth cohort study. Pediatrics. 2007;119(1):e225-31.

4. Kronman MP, Zaoutis TE, Haynes K, Feng R, Coffin SE. Antibiotic exposure and IBD development among children: a population-based cohort study. Pediatrics. 2012;130(4):e794-803.

5. Bailey LC, Forrest CB, Zhang P, Richards TM, Livshits A, DeRusso PA. Association of antibiotics in infancy with early childhood obesity. JAMA Pediatr. 2014;168(11):1063-9.

6. Schwartz BS, Pollak J, Bailey-Davis L, Hirsch AG, Cosgrove SE, Nau C, Kress AM, Glass TA, Bandeen-Roche K. Antibiotic use and childhood body mass index trajectory. Int J Obes (Lond). 2016;40(4):615-21

7. Azad MB, Bridgman SL, Becker AB, Kozyrskyj AL. Infant antibiotic exposure and the development of childhood overweight and central adiposity. Int J Obes (Lond). 2014;38(10):1290-8.

8. Ajslev TA, Andersen CS, Gamborg M, Sorensen TI, Jess T. Childhood overweight after establishment of the gut microbiota: the role of delivery mode, pre-pregnancy weight and early administration of antibiotics. Int J Obes. 2011;35(4):522-9.

9. Trasande L, Blustein J, Liu M, Corwin E, Cox LM, Blaser MJ. Infant antibiotic exposures and early-life body mass. Int J Obes. 2013;37(1):16-23.

10. Scott Fl, Horton DB, Mamtani R, Haynes K, Goldberg DS, Lee DY, Lewis JD. Administration of Antibiotics to children before age 2 years increases risk for childhood obesity. Gastroenterology. 2016;151(1):120-9.e5.

11. Murphy R, Stewart AW, Braithwaite I, Beasley R, Hancox RJ, Mitchell EA. Antibiotic treatment during infancy and increased body mass index in boys: an international cross-sectional study. Int J Obes (Lond). 2014;38(8):1115-9.

12. Gerber JS, Bryan M, Ross RK, Daymon C, Parks EP, Localio AR, Grundmeier RW, Stallings VA, Zaoutis TE. Antibiotic exposure during the first 6 months of life and weight gain during childhood. JAMA. 315(12):1258-65.

13. Saari A, Virta LJ, Sankilampi U, Dunkel L, Saxen H. Antibiotic exposure in infancy and risk of being overweight in the first 24 months of life. Pediatrics. 2015;135(4):617-26.

14. Bervoets L, Van Hoorenbeeck K, Kortleven I, Van Noten C, Hens N, Vael C, Goossens H, Desager KN, Vankerckhoven V. Differences in gut microbiota composition between obese and lean children: a cross-sectional study. Gut Pathog. 2013;5(1):10

15. Santacruz A, Marcos A, Warnberg J, Marti A, Martin-Matillas M, Campoy C, Moreno LA, Veiga O, Redondo-Figuero C, Garagorri JM, et al. Interplay between weight loss and gut microbiota composition in overweight adolescents. Obesity (Silver Spring). 2009;17(10):1906-15.

16. Mekkes MC, Weenen TC, Brummer RJ, Claassen E. The development of probiotic treatment in obesity: a review. Benef Microbes. 2013:1-10.

17. Ley RE, Turnbaugh PJ, Klein S, Gordon Jl. Microbial ecology: human gut microbes associated with obesity. Nature. 2006;444(7122):1022-3.

18. Turnbaugh PJ, Hamady M, Yatsunenko T, Cantarel BL, Duncan A, Ley RE, Sogin ML, Jones WJ, Roe BA, Affourtit JP, et al. A core gut microbiome in obese and lean twins. Nature. 2009;457(7228):480-4.

19. Francino MP. Antibiotics and the human gut microbiome: Dysbioses and accumulation of resistances. Front Microbiol. 2015;6:1543.

20. Rafii F, Sutherland JB, Cerniglia CE. Effects of treatment with antimicrobial agents on the human colonic microflora. Ther Clin Risk Manag. 2008;4(6):1343-58.

21. Principi N, Esposito S. Antibiotic administration and the development of obesity in children. Int J Antimicrob Agents. 2016;47(3):171-7.

22. Cox LM, Yamanishi S, Sohn J, Alekseyenko AV, Leung JM, Cho I, Kim SG, Li $\mathrm{H}$, Gao Z, Mahana D, et al. Altering the intestinal microbiota during a critical developmental window has lasting metabolic consequences. Cell. 2014; 158(4):705-21

23. Lange $K$, Buerger M, Stallmach $A$, Bruns T. Effects of antibiotics on gut microbiota. Dig Dis. 2016;34(3):260-8.

24. Poulsen MN, Pollak J, Bailey-Davis L, Hirsch AG, Glass TA, Schwartz BS. Associations of prenatal and childhood antibiotic use with child body mass index at age 3 years. Obesity (Silver Spring). 2017;25(2):438-44.

25. Ville AP, Heyman MB, Medrano R, Wojcicki JM. Early antibiotic exposure and risk of childhood obesity in Latinos. Child Obes. 2017;13(3):231-5.
26. Mbakwa CA, Scheres L, Penders J, Mommers M, Thijs C, Arts IC. Early life antibiotic exposure and weight development in children. J Pediatr. 2016; 176:105-13 e102.

27. De Onis M, Onyango AW: The Centers for Disease Control and Prevention 2000 growth charts and the growth of breastfed infants. Acta Paediatr 2003, 92(4):413-419.

28. Weng SF, Redsell SA, Nathan D, Swift JA, Yang M, Glazebrook C. Estimating overweight risk in childhood from predictors during infancy. Pediatrics. 2013;132(2):e414-21.

29. Hillier TA, Pedula KL, Schmidt MM, Mullen JA, Charles MA, Pettitt DJ. Childhood obesity and metabolic imprinting: the ongoing effects of maternal hyperglycemia. Diabetes Care. 2007;30(9):2287-92.

30. Dabelea D, Hanson RL, Lindsay RS, Pettitt DJ, Imperatore G, Gabir MM, Roumain J, Bennett PH, Knowler WC. Intrauterine exposure to diabetes conveys risks for type 2 diabetes and obesity: a study of discordant sibships. Diabetes. 2000;49(12):2208-11.

31. Gillman MW, Rifas-Shiman S, Berkey CS, Field AE, Colditz GA. Maternal gestational diabetes, birth weight, and adolescent obesity. Pediatrics. 2003; 111(3):e221-6.

32. Poroyko V, Morowitz M, Bell T, Ulanov A, Wang M, Donovan S, Bao N, Gu S, Hong L, Alverdy JC, et al. Diet creates metabolic niches in the "immature gut" that shape microbial communities. Nutr Hosp. 2011;26(6):1283-95.

33. Luoto R, Kalliomaki M, Laitinen K, Delzenne NM, Cani PD, Salminen S, Isolauri E. Initial dietary and microbiological environments deviate in normal-weight compared to overweight children at 10 years of age. J Pediatr Gastroenterol Nutr. 2011;52(1):90-5.

34. Korpela K, Salonen A, Virta L, Kekkonen RA, de Vos WM. Association of Early-Life Antibiotic use and Protective Effects of breastfeeding: role of the intestinal microbiota. JAMA Pediatr. 2016;170(8):750-7.

35. Fein SB, Labiner-Wolfe J, Shealy KR, Li R, Chen J, Grummer-Strawn LM. Infant feeding practices study II: study methods. Pediatrics. 2008;122(Suppl 2):S28-35.

36. Fein SB, Li R, Chen J, Scanlon KS, Grummer-Strawn LM. Methods for the year 6 follow-up study of children in the infant feeding practices study $\|$. Pediatrics. 2014;134(Suppl 1):S4-S12.

37. Infant Feeding Practices Study II and Its Year Six Follow Up [https://www. cdc.gov/breastfeeding/data/ifps/index.htm].

38. Barlow SE, Expert C. Expert committee recommendations regarding the prevention, assessment, and treatment of child and adolescent overweight and obesity: summary report. Pediatrics. 2007;120(Suppl 4):S164-92.

39. Kuczmarski RJ, Ogden CL, Guo SS, Grummer-Strawn LM, Flegal KM, Mei Z, Wei R, Curtin LR, Roche AF, Johnson CL. CDC growth charts for the United States: methods and development. Vital Health Stat 11. 2000; 2002(246):1-190.

40. Heerman WJ, Bian A, Shintani A, Barkin SL. Interaction between maternal prepregnancy body mass index and gestational weight gain shapes infant growth. Acad Pediatr. 2014;14(5):463-70.

41. Moller SE, Ajslev TA, Andersen CS, Dalgard C, Sorensen TI. Risk of childhood overweight after exposure to tobacco smoking in prenatal and early postnatal life. PLoS One. 2014;9(10):e109184.

42. Yan J, Liu L, Zhu Y, Huang G, Wang PP. The association between breastfeeding and childhood obesity: a meta-analysis. BMC Public Health. 2014;14:1267.

43. Duijts L, Ramadhani MK, Moll HA. Breastfeeding protects against infectious diseases during infancy in industrialized countries. A systematic review. Matern Child Nutr. 2009;5(3):199-210.

44. Briefel RR, Reidy K, Karwe V, Devaney B. Feeding infants and toddlers study: improvements needed in meeting infant feeding recommendations. J Am Diet Assoc. 2004;104(1 Suppl 1):s31-7.

45. Li R, Ogden C, Ballew C, Gillespie C, Grummer-Strawn L. Prevalence of exclusive breastfeeding among US infants: the third National Health and nutrition examination survey (phase II, 1991-1994). Am J Public Health. 2002; 92(7):1107-10

46. U.S. Department of Health and Human Services, Centers for Disease Control and Prevention, Data and Statistics. Breastfeeding Among U.S. Children Born 2001-2011, National Immunization Survey. Available online at: http://www. cdc.gov/breastfeeding/data/NIS_data/index.htm. Last accessed: 13 Dec 2018.

47. Bashiardes S, Thaiss CA, Elinav E. It's in the Milk: feeding the microbiome to promote infant growth. Cell Metab. 2016;23(3):393-4. 
48. Bergmann H, Rodriguez JM, Salminen S, Szajewska H. Probiotics in human milk and probiotic supplementation in infant nutrition: a workshop report. Br J Nutr. 2014;112(7):1119-28.

49. Cunningham SA, Kramer MR, Narayan KM. Incidence of childhood obesity in the United States. N Engl J Med. 2014;370(17):1660-1.

50. Guo SS, Wu W, Chumlea WC, Roche AF. Predicting overweight and obesity in adulthood from body mass index values in childhood and adolescence. Am J Clin Nutr. 2002;76(3):653-8.

51. Risnes KR, Belanger K, Murk W, Bracken MB. Antibiotic exposure by 6 months and asthma and allergy at 6 years: findings in a cohort of 1,401 US children. Am J Epidemiol. 2011;173(3):310-8.

52. Marra F, Marra CA, Richardson K, Lynd LD, Kozyrskyj A, Patrick DM, Bowie WR, Fitzgerald JM. Antibiotic use in children is associated with increased risk of asthma. Pediatrics. 2009;123(3):1003-10.

Ready to submit your research? Choose BMC and benefit from:

- fast, convenient online submission

- thorough peer review by experienced researchers in your field

- rapid publication on acceptance

- support for research data, including large and complex data types

- gold Open Access which fosters wider collaboration and increased citations

- maximum visibility for your research: over $100 \mathrm{M}$ website views per year

At $\mathrm{BMC}$, research is always in progress.

Learn more biomedcentral.com/submissions 